\title{
News and Perspectives
}

\author{
Toshisada Nishida
}

Published online: 25 June 2009

(C) Japan Monkey Centre and Springer 2009

\section{Dear Colleagues,}

For the past 5 years we have successfully maintained the quality of our journal at a higher level than before, due in part to the hard work of associate editors, advisory board members, and outside reviewers. Of course, your submission of excellent papers has been the most important factor in this success. In addition, Springer's staff members with their constant support and, last but not least, my colleague Tamiko Shibata, Editorial Secretary, have contributed immeasurably to the successful publication of the journal. I thank all these individuals for their efforts.

Recently, however, we have felt it necessary to restructure what has been the Short Communications section because many authors seemed to regard it as a forum for a short, lower-quality contribution or for a case study.

We now are considering establishing what in effect will be a new forum to be called News and Perspectives instead of Short Communications.

The purpose of this new forum is the publication of (1) research reports with high news value that stimulate further research, and (2) papers that view known topics from different perspectives and/or with new theoretical considerations. In either case, authors are requested to submit short papers with high scientific/news value.

Case studies will be accepted only if (1) their observational data are excellent and (2) the resulting theoretical implications are important and clearly presented.

The maximum length of a paper will be 18 manuscript pages ( 6 printed pages), instead of 12 manuscript pages (4 printed pages) for the former Short Communications section.

We will expedite the publication of papers submitted to this forum, our aim being to publish them online within 3 months after they have been submitted to us.

We are always grateful for your support for Primates, and we welcome the submission of your important papers to this new forum.

\section{Toshisada Nishida \\ Editor-in-Chief \\ Primates}

T. Nishida $(\square)$

Japan Monkey Centre, Inuyama, Japan

e-mail: nishida@jinrui.zool.kyoto-u.ac.jp 